\title{
Reconsiderando la literatura testimonial
}

La literatura testimonial suele entrañar algunas ambivalencias. Por un lado, parece revestirse de un exceso de humildad. Se suele afirmar que el texto testimonial carece de pretensiones literarias. Esto viniendo de algunos autores de testimonios puede ser una confesión sincera. El testimonio es un primer aporte a la cultura, un aporte en bruto, sobre experiencias hasta entonces escondidas, negadas. Por el otro lado, sin embargo, los críticos -aquellos que han hecho carrera del estudio del Testimonio- nos presenta la otra faz, y la humildad se vuelve exceso de arrogancia. El testimonio carece de pretensiones literarias porque es "más que literario". El Testimonio resulta ser una práctica escritural que trasciende los asfixiantes límites de la autonomía artística para convertirse, en pocas palabras, arte vuelto vida.

Al superar los límites de un arte autónomo y, por tanto, divorciado de la praxis social, el testimonio queda, por su parte, exento de las tribulaciones del juicio estético. Intentar valorar estéticamente un testimonio es poco menos que una escandolosa obscenidad, una muestra de grosera de incorrección política. El texto vale por la veracidad de la vivencia que transmite y, sobre todo, por la corrección de la opción política de su autor. Siendo las cosas así, ¿qué importa si el testimonio está mal escrito? Más aún, estar mal escrito se vuelve un punto a su favor, un elemento que mantiene el aura de autenticidad con que el testimonio se empaca y despacha para su consumo por las almas que simpatizan con las causas progresistas de la humanidad.
Esta concepción del testimonio -que, como he dicho, se encuentra menos entre quienes lo practican que entre quienes lo promueven en el interior de la institución académica - tiene implicaciones que no deben tomarse a la ligera. Mal comprenderíamos si la redujéramos a un asunto de género literario, es decir, a la situación problemática del testimonio entre géneros narrativos habituales, tales como la novela, la confesión, la autobiografía o el relato periodístico. El testimonio se presenta así tanto como una nueva forma de hacer literatura y de adjudicar valor literario.

¿A qué nos referimos con ellos? Pues a que estamos ante una Literatura que renuncia a la autonomía, es decir, que abandona la consistencia interna como criterio de valor fundamental. En cambio, tenemos una literatura plenamente heterónoma, donde la norma la establecen criterios sobre todo políticos e ideológicos. La Literatura testimonial así concebida encaja a la perfección dentro de la corriente de los estudios literarios que ataca ferozmente la estética idealista que comenzara a forjarse desde el siglo XVIII. Según estos teóricos, el valor estético es una mera ilusión ideológica, cada ideología y grupo de poder produce sus propios criterios de valor y jerarquía. Al negarse la especificidad de lo estético, nos quedamos ante una crítica que evalúa los productos de la cultura con base en parámetros exclusivamente políticos.

No es casualidad que el testimonio haya adquirido tanta relevancia en el clima cultural dominado por la posmodernidad. Los impulsadores del 
testimonio suscriben la postura postmoderna de relativismo cultural. Partiendo de que es imposible establecer criterios únicos y estables de valor, adoptan un eclecticismo radical. Puesto que las normas de valor estético de la institución literaria vigente están comprometidos con el poder, negarlos se convierte en un gesto indiscutiblemente revolucionario. Sin embargo, su relativismo es limitado. Si bien se rechaza establecer cualquier jerarquía en el terreno cultural, lo mismo no sucede en el político. Así, los textos calificados de revolucionarios son buenos, mientras que los tildados de reaccionarios o-quizá peor- de ascépticosa, lo son menos. Críticos confesos del canon y la jerarquía, estos críticos fundan - tal vez sin darse cuenta- las bases de nuevos cánones y nuevas jerarquizaciones.

La pregunta pertinente dentro de todo esto atañe las repercusiones prácticas de esta nueva concepción de lo literario. En otras palabras, conviene examinar si concepciones como la que sustenta la Literatura Testimonial representan un avance respecto a las estéticas precedentes $y$, sobre todo, respecto a la institución literaria autónoma que atacan. Un punto central es determinar qué ganamos y qué perdemos al desterrar las consideraciones estéticas - heredadas de la tradición idealista - en la reflexión sobre la creación artística y literaria. Dentro del horizonte cultural que hemos vivido, los criterios de valor artístico han sido autónomos. Se supone que un texto artístico es valioso en cuanto responda a las exigencias propuestas por la propia actividad artística en que se inserta. Estas exigencias son, en primer lugar, de índole técnicoformal. No debemos olvidar que el arte es primero que nada una técnica, un oficio que demanda habilidad. Pero también suelen estar presentes otras consideraciones. En el arte moderno, la originalidad y la autenticidad son demandas fundamentales. Estas dos últimas consideraciones implican necesariamente aspectos de contenido. Según algunos teóricos, el arte no se limita a ser mera forma ni mero contenido. El arte debe aspirar a una cierta solidaridad entre forma y contenido. Estamos, pues, ante lo que algunos han llamado el problema de la verdad estética. Así, se opondría el lenguaje literario donde hay esta voluntad de verdad artística al lenguaje cotidiano-instrumental donde predomina la convencionalidad, y la exterioridad de la forma con respecto al contenido.

Llegar al contenido auténtico a través de lo formal, de la exploración de la figuración es un criterio de valor estético que define claramente el movimiento de nuestra modernidad cultural, desde sus albores en el clasicismo hasta su pleno despliegue a partir de la revolución romántica. Se enfrentan evidentemente a esta tradición los movimientos de vanguardia más iconoclastas, cuyo objetivo es la destrucción de la forma, la destrucción de la obra artística. Es importante subrayar que este criterio de valor estético no supone necesariamente la exclusividad del arte de élites ni la exclusión del arte de factura y consumo popular. $\mathrm{Si}$, históricamente hablando, la cultura emancipadora de la modernidad ha sido secuestrada por las élites para legitimar su poder, ello es un problema aparte. El punto es que esta concepción de valor estético es, contrario a las apariencias, bastante pluralista y bastante democrática. Pluralista, por cuanto no establece normativas a priori: cada obra se debe valorar en sus propios términos. Democráti$\mathrm{ca}$, por cuanto el valor estético se tiene que decidir por los logros del producto, y no por el origen de quien lo fabrica. Además, al rechazarse de principio toda preceptiva, se abre la posibilidad de hacer de la actividad artística una práctica emancipadora, que dirige sus esfuerzos a romper las imágenes autocomplacientes que todo orden social crea de sí mismo.

En la Literatura Testimonial tenemos claramente una inversión de estos términos. En primer lugar, la normativa la establece el proyecto político-ideológico que sustenta el testimonio. El testimonio vale en cuanto es más progresista, es decir, en cuanto es más afín a concepciones de la humanidad y la historia fijadas fuera del producto artístico y la visión de mundo que éste articula en su propia construcción. En segundo lugar, al negarse la ficcionalidad del relato testimonial se apela a un cierto fetichismo de la voz del testimoniante. El relato ya no vale en función de lo verosímil del mundo imaginario que recrea, sino en función de la veracidad referencial de lo contado. Con esto no quiero decir que se excluya totalmente de la reflexión sobre el testimonio sus méritos constructivos, sino que estos quedan totalmente supeditados a la utilidad política y de una verdad establecida por un pacto de fe entre lector y texto.

Para tener en cuenta claramente las implicaciones de este cambio de actitudes propongo examinar un texto testimonial que ha tenido un impacto relativamente considerable en El Salvador. Me re- 
fiero a No me agarran viva de Claribel Alegría y D. J. Flakoll. Doy por hecho que la efectividad política de ese texto es innegable. Nadie puede permanecer indiferente ante la conmovedora historia de Eugenia y ante las viscitudes que debieron enfrentar ella y sus compañeras de lucha. El libro impresiona porque la realidad a la que se refiere es impactante. Si el lector tiene simpatías políticas por la causa asumida por el texto, es indudable que le conmoverá y le afirmará en sus convicciones. Esto resulta especialmente cierto para el lector contemporáneo a la publicación del texto. Sin embargo, un lector perteneciente a nuestra contemporaneidad lo abordaría desde un horizonte de recepción afectado por el proceso de paz y de integración de la izquiera revolucionaria a la vida política nacional, por lo que no es arriesgado anticipar que sus reacciones serían distintas. Seguramente la empatía cedería ante una actitud un poco más distanciada y escéptica.

La primera impresión que nos resulta de releer No me agarran viva es que pese a su relativa novedad --el libro fue publicado hace poco más de diez años - es una obra envejecida, una obra que ya agotó su actualidad. Ya cumplió su función y que las exigencias de la historia han cambiado. $\mathrm{Si}$ era una obra del aquí y del ahora, hemos de concluir que vivimos en coordenadas definitivamente alteraclas. Sin embargo, creo que podemos tener una mayor comprensión del sentido del texto y de sus limitaciones para trascender el contexto más inmediato de su publicación, si tratamos de establecer su verdad artística como función de una complementariedad orgánica entre sus mecanismos constructivos y la visión de mundo que se intenta vehicular a través de él.

No me agarran viva tiene una concepción bastante ingeniosa y original si se le compara a otros textos que se han publicado bajo la etiqueta de Testimonio. Sus autores son escritores profesionales con logros literarios importantes y poseen indiscutiblemente las habilidades para emprender un reto de esta magnitud. No me agarran viva tiene una estructura que recuerda a los relatos policiales o la de ciertos reportajes periodísticos. El proceso de construcción de la historia es parte del relato. El texto de manera bastante deliberada intenta hacer partícipe al lector de esta búsqueda. No me agarran viva comienza con un primer capítulo donde un narrador omnisciente nos entrega de manera bastante ágil y objetivista la secuencia final

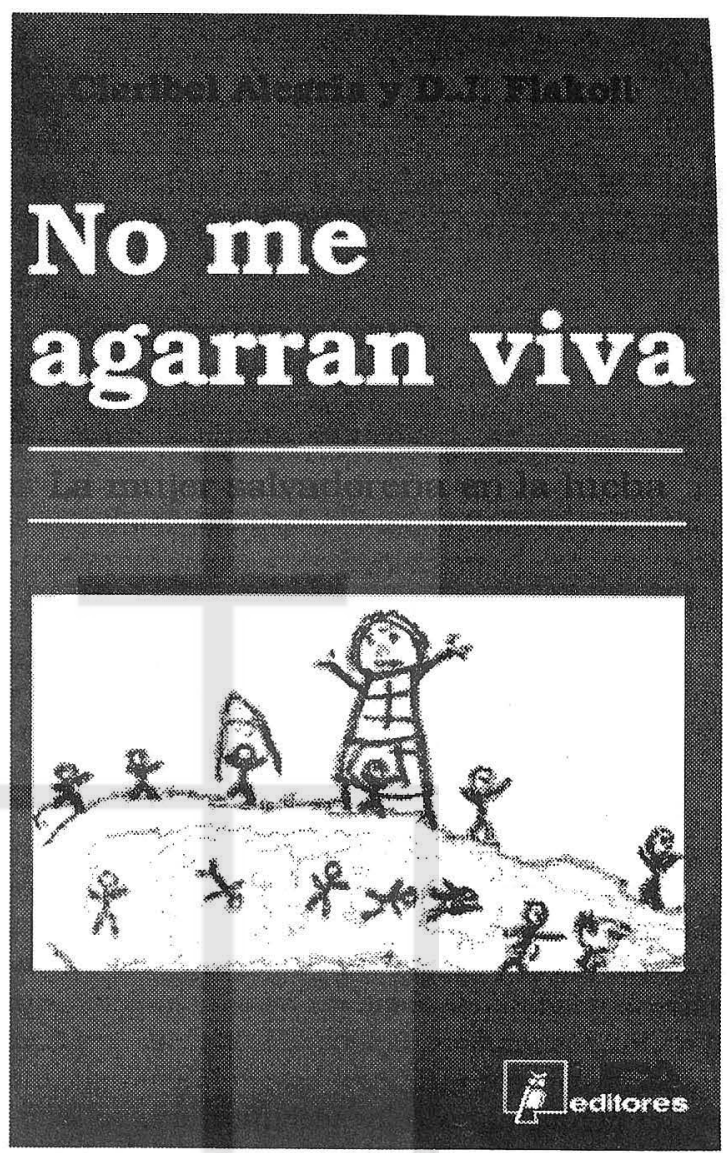

de la historia de la heroína, la última misión de la joven guerrillera, la misión en la que habrá de morir heroicamente. El relato se suspende poco antes del desenlace, para dar lugar a una larga retrospección que constituye el cuerpo principal del texto. Este cuerpo tiene una estructuración más ambiciosa. Estamos ante una suerte de polifonía entre, por un lado, la voz del narrador principal que reconstruye la biografía de Eugenia y narra la historia del proceso revolucionario salvadoreño $\mathrm{y}$, por otro, los testimonios de varios informantes que cuentan en sus propias palabras sus recuerdos de Eugenia y sus vivencias del proceso histórico.

Esta concepción es ingeniosa porque vislumbra un mecanismo potencialmente fructífero para combinar materiales bastante diversos. Además, hay un salto desde el primer capítulo donde tenemos la conciencia del narrador-investigador como única perspectiva hasta una presentación más polifónica, más pluriperspectivista. El relato testimonial nos promete pues una especie de desmon- 
taje del género reportaje, estilizado literariamente en el primer capítulo. Así, la materia prima - los testimonios - nos debería restituir una perspectiva más profunda y compleja que la que podría entregarnos el afán de objetividad del reportero. Al parecer, de manera bastante inteligente el texto se habría valido de moverse entre las fronteras de géneros de la ficción, como la novela, y los géneros no-ficticios, como el relato periodístico para darnos una visión más rica de la realidad. De lograr esto, poco importaría si No me agarran viva se ubicase dentro de la ficción novelesca o si fundara un nuevo género; sería Literatura en el sentido más extremo: búsqueda de la autenticidad en tensión con los géneros y las convenciones establecidas por la Institución Literaria.

Desgraciadamente esto no es así. El diseño le queda demasiado grande al universo que logra abarcar el relato. Tenemos una estructura demasiado compleja -concebida para contener una realidad heterogénea y diversa- pero la tenemos sobrepuesta a un universo ficcional donde predomina la monocronía. El diseño polifónico no logra más que transmitir un confuso unísono de clichés, dogmas, retórica panfletaria y los más gastados lugares comunes del romanticismo revolucionario. Así, los testimonios de los informantes resultan sospechosamente idénticos, hasta el punto que, de no ser porque el texto los identifica, uno se sentiría inclinado a pensar que provienen de la misma persona. La sensación de incomodidad que esto produce resulta verdadermente insoportable cuando el narrador se contamina de la misma retórica y parece utilizar las voces de los informantes únicamente para confirmar ideas que carga desde el principio. Si este narrador intentaba estilizar al reportero o al investigador científico, esta fácil identificación con la ideología de sus entrevistados le hace perder autoridad. No hay nada de reprochable en la simpatía de los autores por la causa de la heroína, el problema es que una cosa son ellos como personas y otra la convención literaria que emplean para articular su texto. Desafortunadamente para el texto, las voces del narrador, los personajes y los informantes se funden en una poco eufónica monodia donde se canta a las verdades eternas del materialismo dialéctico y de la guerra popular prolongada.

Dentro de este mundo donde ya todo está resuelto de entrada, resultan también inmotivados recursos como el flash-back y las múltiples pers- pectivas. Eugenia es siempre la misma: la santa, la sacrificada, la revolucionaria en ciernes desde su pasado católico. Ella no duda jamás de sus convicciones, sólo de su propia capacidad para llevar a cabo las tareas que la historia o el partido le ponen por delante. Es un personaje que no evoluciona, que no sufre un verdadero proceso en el interior del relato. Las coordenadas de su vida están dadas desde el inicio y son repetidas y confirmadas a cada paso del relato.

El relato adolece, además, de otras fallas todavía más visibles. En primer lugar, cabe indicar el contrapunto de la mitología revolucionaria sobre la historia salvadoreña: un añadido que podría suprimirse sin que el texto se viera seriamente comprometido. Parece tener más bien la función didáctica de orientar a los lectores menos familiarizados con la historia de El Salvador. Sin embargo, su relación con la vida de la heroína es bastante débil, opera por pura contigüidad y sólo sirve para reforzar la teleología de la doctrina de la guerra popular prolongada - lo que parece ser uno de los propósitos no confesos del libro. Asimismo, forzadas $\mathrm{y}$, en determinado momento, cansadas resultan las impredecibles digresiones de algunos informantes que abandonan totalmente el hilo de la vida de Eugenia para hablar de otros temas concernientes a la revolución salvadoreña que podrán ser interesantes pero afectan negativamente el diseño del texto.

En definitiva, este examen de los logros estéticos de No me agarran viva nos revela no simplemente defectos de ornato, de acabado. La calidad literaria de un texto no se refiere a vestir un hermoso ropaje sino a la consistencia del texto mismo, a su verdad artística. Consecuentemente, sus defectos afectan su captación de la realidad y, en última instancia, su efectividad. No dudo que la vida de Eugenia fuera interesante y ciertamente digna de inspirar la mejor literatura. Desafortunadamente, No me agarran viva le hace poca justicia. Prueba de ello es la pérdida de actualidad del relato. En la medida que el curso de la historia de los últimos años ha terminado por relativizar las verdades sobre las cuales se asienta el texto, éste pierde interés, pierde potencia, y pierde ciertamente la ejemplaridad a la que en su momento aspiró. La vida de Eugenia, tal como nos es entregada por el relato, pertenece a las hagiografías y los santorales, no al reino de este mundo.

Las pretensiones postmodernas de la llamada 
literatura testimonial quedan, al menos en este caso, desenmascaradas como raigalmente pre-modernas: son menos una radicalización de las vanguardias que una regresión al universo de la heteronomía, es decir, a la servidumbre ideológica y moral del quehacer artístico. La concepción estética de la Literatura Testimonial revela limitaciones obvias respecto a su enemigo confeso: la Nueva Novela. ¿A dónde está la realidad compleja, multiforme que el realismo se empeñó en reconstruir literariamente? ¿A dónde la conciencia del lenguaje, la determinación intersubjetiva de lo real que el modernismo se empeñó en plasmar? Estamos, a cambio, de regreso en el mundo de los dogmas, de las verdades absolutas y de su ilustración en ejemplos. Parafraseando a Lukács, diríamos que seguimos en un mundo degrado pero tenemos a cambio un héroe - en este caso una heroína- aproblemático que ya encontró sentido en Dios o en el Partido.
Para concluir, he de aclarar que no pretendo hacer una condena total de la Literatura Testimonial. Creo que hay testimonios interesantes y bien logrados. Creo, asimismo, que el fenómeno del testimonio ha tenido secuelas positivas. La principal ha sido llamar la atención sobre un área de la experiencia social ignorada o pasada por alto por círculos artísticos demasiado interesados en estar a la altura de los últimos llamados de la moda literaria. He intentado, sin embargo, señalar las limitaciones de los reclamos de quienes han pretendido hacer del Testimonio la panacea para la redención de la Cultura. Sus argumentos nos recuerdan demasiado a los de ciertos abogados del realismo socialista. El arte contemporáneo se encuentra en uno de sus atolladeros más difíciles. Sin embargo, la servidumbre a proyectos dejados atrás por la historia no será jamás una verdadera alternativa.

Ricardo Roque Baldovinos

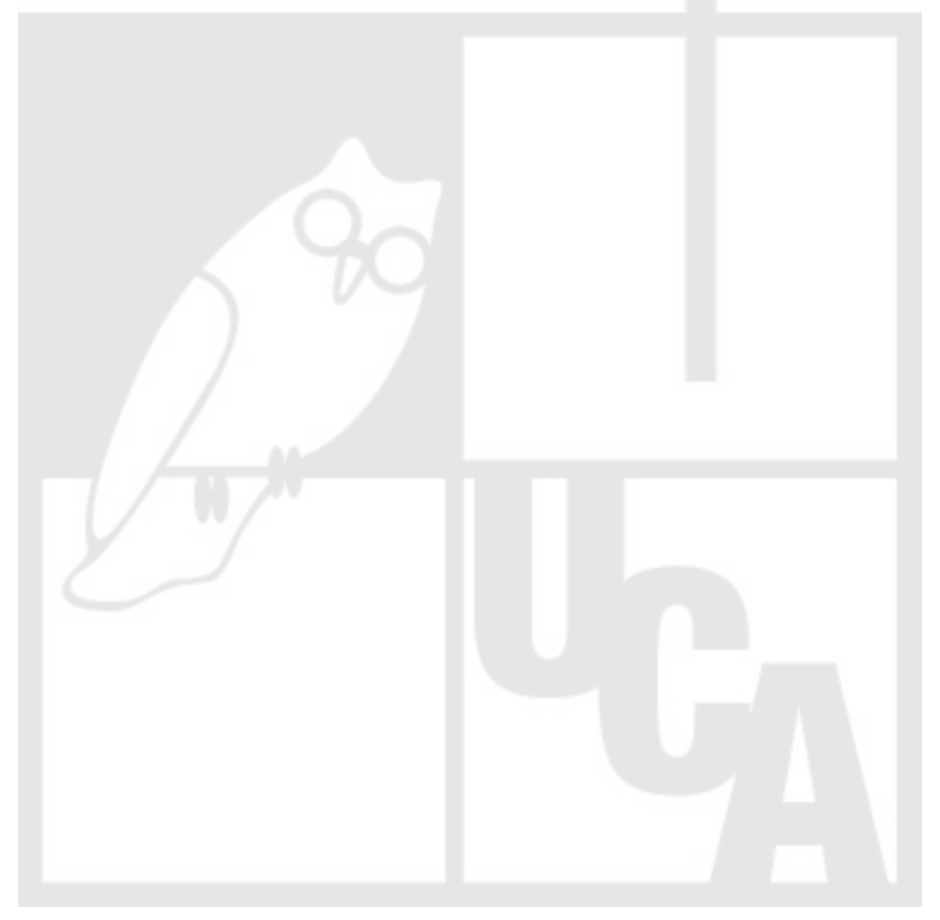

